\title{
BREVES APONTAMENTOS SOBRE A INCIDÊNCIA VALORATIVA NA NOMOGÊNESE E SUBSUNÇÃO
}

\author{
Fabiana Vergílio Souto, Augusta Rodrigues Westin Ebaid \\ Universidade do Oeste Paulista - UNOESTE, curso de Direito, Presidente Prudente, SP. E-mail: \\ fabianavergiliosouto@hotmail.com
}

\begin{abstract}
RESUMO
A questão do valor, em relação ao Direito, se manifesta em dois momentos distintos, todavia igualmente relevantes: o primeiro, quando a norma é produzida (nomogênese); o segundo, quando ela é aplicada (subsunção). A questão-problema surge também sob dois ângulos diferentes: o da justiça, valor supremo no âmbito jurídico e o da legitimidade.

Os resultados obtidos apontam para a constatação de que as forças sociais e todo o poder imanente do povo impulsiona o Poder Legislativo, gerando a necessidade de efetivar a nomogênese, que corresponda às necessidades sociais. E que, em um momento posterior, a ideologia do julgador, condicionada por dados culturais nos processos de socialização, norteia a subsunção.

Para dar seguimento e fundamentação teórica a presente pesquisa, utilizou-se como principal mecanismo de investigação, a busca de material bibliográfico, mais especificamente livros escritos, e do formato digital, enfatizando as doutrinas e autores prestigiados.
\end{abstract}

Palavras-chave: Direito, nomogênese, subsunção, moral, valores.

\section{BRIEF POINTS ON VALUE INCIDENCE IN NOMOGENESIS AND SUBSUNITION}

\begin{abstract}
The question of value, in relation to law, manifests itself in two distinct but equally relevant moments: the first, when the norm is produced (nomogenesis); The second, when it is applied (subsumption). The problem question also arises from two different angles: that of justice, supreme value in the legal sphere and that of legitimacy.

The results obtained point to the realization that the social forces and all the immanent power of the people impels the Legislative Power, generating the necessity of effecting the nomogenesis, that corresponds to the social needs. And that, at a later moment, the ideology of the judge, conditioned by cultural data in the processes of socialization, guides the subsumption.

In order to follow up and theoretical basis of the present research, the search for bibliographical material, more specifically written books, and the digital format, emphasizing the prestigious doctrines and authors was used as the main mechanism of investigation.
\end{abstract}

Keywords: Right, nomogenesis, subsumption, moral, values.

\section{INTRODUÇÃO}

O ensaio jurídico, no sentido de experiência do Direito na realidade, deve ser ponderado sob a ótica de duas ideias iniciais: apreciação fenomenológica da realidade e a cogitação como vigência no processo das ideias, ou seja, o Direito possui um intenso elemento histórico, que necessariamente deve ser estudado juntamente às valorações, coligado ao contexto da época em que o fato se verificou.

O homem nunca se desata do contexto social e histórico, das conjunturas que o abarcam na vida em sociedade. Não há como se libertar totalmente de forças do passado que agem como 
processos e costumes vagarosamente estabelecidos e organizados, como vínculos habituais, que a cultura conserva e conduz de uma geração a outra. São forças contemporâneas com sua importância histórica (REALE, 2002, p. 377).

\section{INCIDÊNCIA VALORATIVA NA NOMOGÊNESE E SUBSUNÇÃO}

Os valores podem ser entendidos, mesmo no âmbito jurídico como aquilo que na concepção de determinado grupo social se apresenta como condicionante de perfectibilização para a coletividade que integra tal grupo (COSTA, 1996, p. 46).

Conforme Reale (1990, p. 368),

O Direito, portanto, possui conteúdo histórico que nos cabe analisar como conjunto de significações, e não apenas como sequência mais ou menos regular de fatos. Não basta, por conseguinte, acolher um fato como se fosse jurídico, pois importa verificar como é que foi 'recebido' como tal através do tempo. A compreensão histórico-axiológica deve completar a outra, ou seja, a resultante da descrição e da redução fenomenológica, insuficiente porque revelada de maneira estática, posto entre parêntesis o elemento dinâmico da História: no ato em que o objeto de uma pesquisa histórico-cultural se reflete na consciência transcendental, esta se põe como temporalidade. (sic)

É como se o ser humano fosse o valor principal, ou seja, algo que vale por si mesmo. Dentre todos os seres, apenas o homem é capaz de valores, de estimá-los ou desconsiderá-los.

A norma jurídica tem uma natureza sui generis, na medida em que não é uma substância material, nem é puro pensamento, puro sentido de um ato, nem esquema de interpretação, nem simples conceito, mas algo que vibra na consciência coletiva de normatividade, consciência de normatividade palpitante em todos e cada dos que, no grupo social, aceitam, toleram ou suportam, obedecendo aos conteúdos normatizados (COSTA, 1996, p. 99).

A axiologia jurídica implica questões-problemas atinentes ao cerne de algo que se valora, considerando a importância histórica que contorna o ser humano e gerando um foco de abalançamento que norteia seu conceito de vida.

Abrolham duas formas de abordagem do Direito: as definições valorativas, tais como as deontológicas, e as avalorativas, tais como as ontológicas. As definições valorativas têm uma composição teleológica e descrevem o Direito como um ordenamento que torna possível o alcance de valores almejados. Por outro lado, as definições avalorativas consideram o Direito de forma pura e exclusivamente fatual, autônomo de escopo específico ou valor (VASCONCELOS, 1998).

Como apoiadores notórios das definições valorativas podem ser citados como exemplos Aristóteles, Gustav Radbruch (1997, p. 110) - "Direito é a realidade que tem seu significado no servir ao valor jurídico, isto é, à ideia de justiça" -, Immanuel Kant (2003, p. 76) - "O Direito é o conjunto das condições por meio das quais o arbítrio de um pode entrar em acordo com o arbítrio do outro, segundo uma lei universal da liberdade". Verifica-se o destaque da ideia de que o Direito serve como uma ponte para se alcançar determinados valores.

Quanto aos defensores das definições avalorativas podem ser citados Thommas Hobbes, Austin e Hans Kelsen (1995, p. 19) - "O Direito é a técnica social que consiste em obter a desejada conduta dos homens mediante a ameaça de uma coerção a ser aplicada em caso contrário".

No multiverso jurídico, os valores podem ser avaliados sob a ótica de uma realidade perceptível, aprovando ou desaprovando a estimativa comum de determinadas condutas. Nessa 
acepção, o Direito consiste em um dever-ser e não um ser, na medida em que molda e direciona a performance social.

A atitude dos operadores do Direito deve ser moderada por uma assumida de posição ante os fatos que, no dinamismo social, se aludem a valores, confirmando desta forma a importância da Teoria dos Valores para o multiverso jurídico, uma vez que exprime um dever-ser.

Para que o Direito seja aplicado, deverá ser interpretado na medida em que se adeque melhor ao fato, sendo imprescindíveis as reivindicações axiológicas para adequar o seu teor normativo à realidade. Complementa ainda que,

[...] a base da norma é o fato, sem dúvida, mas o fato axiologicamente dimensionado. Essa apreciação se dá quando do surgimento da norma, renova-se todas as vezes que ela é aplicada: os fatos e valores originais são trazidos à compatibilização com os fatos e os valores do momento presente. Esse processo evidencia o dinamismo do Direito e responde por sua vitalidade (VASCONCELOS, 2006, p. 18).

A concepção acerca da "unidade do ordenamento jurídico" não é uma compreensão específica do positivismo jurídico. A dessemelhança de enfoque entre jusnaturalistas e juspositivistas se dá nos imediatos apontamentos: para os primeiros, se trata de uma unidade substancial, que se pauta rigorosamente no conteúdo, no teor. Para os positivistas é uma unidade formal, o modo pelo qual as normas são assentadas.

As normas jurídicas são imprescindíveis, o que não quer dizer que sejam o único objeto das atenções do especialista do Direito, que há de compreendê-las há luz da realidade factual nelas disciplinadas e dos valores que orientam esse disciplinamento.

A partir de sua organização aberta, o multiverso jurídico, agrupando intensa carga axiológica, é visto como ele deve ser. Os princípios são percebidos como estruturas de orientação e condução do direito, como uma bússola, emanando os valores que lideram a criação do ordenamento jurídico, podendo constar expressamente do texto constitucional, como é o caso do princípio da dignidade da pessoa humana, ou tacitamente como acontece com o princípio da proporcionalidade. Seu teor é de forte carga axiológica permite que a Constituição siga a dinâmica social sem se tornar retrógrada.

Imprescindível se faz lembrar que sob a norma, encontram-se contidos tanto os princípios quanto as regras, sendo as cominações situadas no plano do dever-ser e seus juízos estabelecidos pelo meio dos modais deônticos do proibido, admitido e obrigado.

O Direito que, como norma, brota da consciência de normatividade da sociedade, o Direito que se faz carne em cada direito-subjetivo que se revela, esse Direito, ou se transfigura numa conduta juriforme ou ressuscita com glória, quando a sentença judicial irreversível e não viciada faz a epifania do bem normado (COSTA, 1996, p. 94-95).

O fato de estar vinculada a valores, não quer dizer que todas as normas estejam adequadamente relacionadas ao bem comum, finalidade última do Estado. A atribuição pelo legislador de uma propriedade condicionante de perfectibilização ao objeto escolhido para ser normado, tal atribuição acompanha a intuição axiológica vigente num determinado estágio de evolução cultural, ou num determinado espaço geográfico e dela resulta; sendo que, em qualquer contingência, o desejo e o valor seguem-se ao conhecer (COSTA, 1996, p. 30).

A nomogênese jurídica corresponde ao processo de elaboração de uma norma jurídica. Quando se debate um projeto de lei, nota-se que sobre cada complexo fático sucedem outros tantos complexos axiológicos, mais especificamente, cada indivíduo - em especial aqueles detentores do poder-dever de legislar - tem seu próprio entendimento sobre cada um dos temas em debate e ponderação. Contudo, há de chegar um momento no qual os legisladores escolham 
por uma das opções avaliadas. Nesse momento, quando uma das opções é eleita, todos os demais valores que giravam em torno do objeto-problema são renunciados (REALE, 2002).

Sobre a incidência dos valores na nomogênese jurídica, o nascedouro legal, há que se falar nas forças sociais que atuam fortemente sobre a legislação, impulsionando a criação das normas em prol do bem comum, finalidade última do Estado. Aponta Nunes (2015, p. 179-180):

É certo que existem alguns fatores que influenciam na criação de leis e que existem outros que denunciam sua finalidade. É certo também que alguns indivíduos na sociedade podem exercer pressão, tanto na criação como na revogação de leis. É verdade, também, que existem fatores com origem nos relacionamentos interindividuais e coletivos dentro do meio social como o econômico, por exemplo - que têm força para influir na legislação, sem falar, evidentemente, dos meios de comunicação, que, aliados ao poder econômico, subordinam o poder estatal e a população aos seus interesses.

A ordem jurídica, quando positivada emana da opinião pública e ao mesmo passo que determina as condutas permitidas e proibidas, está submetida às demandas sociais, que definem seus teores, mantimento e reforma. ${ }^{1}$

É relevante lembrar que a opinião pública, muitas vezes, é o reflexo da imposição de certos valores pelos suportes midiáticos, e por outros titulares do poder de veiculação.

A opinião pública desempenha papel fundamental na nomogênese jurídica, sobretudo nos Estado de regime democrático-liberal, onde as leis são elaboradas pelos representantes dos cidadãos (NUNES, 2015, p. 180).

Quaisquer que sejam as divergências sobre a essência e especificidade do que se deva entender por valor, resta uma verificação que pode ser aceita sem discussão: todo fato que, aos olhos de um grupo, se apresente como condicionante de perfectibilização para os integrantes do mesmo, e cuja conservação está condicionada a condutas livres dos homens, visualiza-se como valor, como aquilo que deve ser defendido, assumido e mantido, podendo, certamente, ser obstaculizado por condutas indesejáveis (COSTA, 1996, p. 44-45).

As aspirações sociais são representadas pelo Poder Legislativo e, consequentemente, pelo Executivo, os quais irão elaborar leis em nome da população, mesmo que a representatividade não seja real, mas apenas formal.

Nesse sentido, a opinião pública, formada por um conjunto de valores, ${ }^{2}$ tem inestimável relevância na criação das leis, ou seja, nomogênese jurídica, como ponto principal do exercício daqueles que detém a representatividade do povo. Por isso, aquele que almeja ser eleito, objetivando determinar regras e conduzir um grupo social, tem de ter a opinião pública em seu favor.

Nesse aspecto, um exemplo seria determinada lei que formalmente parece algo que se relaciona com o meio social com o qual deveria de fato estar intimamente ligada, mas na realidade é reflexo de situações reais obscuras, tal como a questão do político vendido à opinião pública como um produto que servirá para algo, mas que de fato na fará (NUNES, 2015, p. 181).

\footnotetext{
${ }^{1}$ Conforme o parágrafo único do art. 1ㅇ da Constituição Federal: “Todo o poder emana do povo, que o exerce por meio de representantes eleitos ou diretamente, nos termos desta Constituição".

${ }^{4}$ Os fatos valorados condicionam a criação das normas, desempenhando uma função de matéria prima do Direito. 
Com isso, a opinião pública constituída por uma conjuntura axiológica exerce efetivamente pressão sobre a lei no momento de sua elaboração e aplicação - nomogênese e subsunção, respectivamente - mas por outro lado, essa opinião pública pode ser ofuscada ou mesmo sua verdadeira força pode ser deturpada pelos suportes midiáticos.

Em síntese, ao surgir um fato novo, surge a necessidade de ter uma norma para lidar com ele. Então são atribuídos um ou mais valores a ele, que podem ser pessoais ou culturais. ${ }^{3}$ Automaticamente, várias normas são pensadas a respeito de tal fato, fundando-se nos valores conferidos a ele (REALE, 2002).

Nem toda valoração ou preferência individual acaba por se transformar no "complexo de valores" ${ }^{4}$ de cada grupo social. Para que isso aconteça, é preciso que a valoração esteja revestida de significação, isto é, que desempenhe um papel de relevo na história.

Ideologia pode ser entendida como um conjunto de convicções e conceitos - concretos e normativos - que aspira elucidar fenômenos sociais complexos com a finalidade de nortear e simplificar as escolhas sociais e políticas que se oferecem a indivíduos e grupos (NUNES, 2015).

Segundo o entendimento acerca da ideologia, ensina Ferraz Júnior (2015, p. 182-183):

A ideologia é um termo equívoco, significando ora falsa consciência, ora tomada de posição - filosófica, política, pessoal, etc. - ora instrumento de análise crítica - teoria da ideologia - ora instrumento de justificação programa de ação. Em nossa concepção, funcionalizamos o conceito. Admitindo-o como um conceito axiológico, isso é, a linguagem ideológica é também valorativa. Só que enquanto os valores em geral constituem critério de avaliação de ações, a valoração ideológica tem, por objeto imediato os próprios valores, como uma qualidade pragmática diferente; enquanto os valores são expressões abertas, reflexivas e instáveis, a valoração ideológica é rígida e limitada.

Uma das observações em que Tércio Ferraz Júnior persiste é que a ideologia enquanto critério científico possibilita o encobrimento dos problemas e de certos conflitos. Além de camuflar problemas do próprio ordenamento jurídico, a ideologia paralisa a busca de soluções, afetando assim não a disposição do sistema de se autorregular, mas do sistema estar acessível à crítica.

Sobre a interpretação jurídica no momento que antecede a subsunção, doutrina Nunes (2015, p. 317):

As normas jurídicas, inseridas num sistema jurídico, são interpretáveis, e o são forçosamente interpretadas por tantos quantos se utilizem e pensem o Direito. Aliás, a chamada Ciência do Direito é, em grande parte, voltada para o ensino de regras técnicas de interpretação do sistema jurídico, não só como um todo, mas também nos seus chamados vários subsistemas internos. A doutrina corrente diz que interpretar significa fixar o sentido de alguma coisa. Quem interpreta busca captar do objeto de interpretação sua essência e coloca-la de forma traduzida como um novo plano de entendimento. Em outras palavras, interpretar é extrair do objeto tudo aquilo que ele tem de essencial.

\footnotetext{
${ }^{5}$ Subentende-se que não é possível ter diversas normas regulando um mesmo fato. Logo, deve existir um fator prevalecente. Escolhe-se, então, um deles e cria-se a norma, que deverá ser única (REALE, 2002).

${ }^{6}$ Conjuntura valorativa cultuada por determinado grupo social.

Colloquium Socialis, Presidente Prudente, v. 01, n. Especial 2, Jul/Dez, 2017, p.229-235. DOI: 10.5747/cs.2017.v01.nesp2.s0141
} 
A ideologia oferece a função organizacional dos valores, admitindo uma sistematização notável, o desenvolvimento de hierarquia, o que denota a possibilidade de acumular interesses e de sua concretização, desempenhando notória função no momento da interpretação legal, fixando um sentido para além da técnica jurídica.

A incidência ideológica desempenha um papel de bússola valorativa, norteando interpretação. Se houver dúvida em uma determinada hipótese, seguramente, prevalecerá aquela em que a ideologia sugere como mais adequada, já que é ela que define o curso da interpretação axiológica e influencia na aplicação da norma jurídica (FERRAZ JÚNIOR, 2015, p. 183).

Congruente a tal ideia, a ideologia serve como mecanismo para desenvolver a interpretação da forma mais apropriada possível, observando-se determinados limites, considerando que,

[...] o intérprete para fazer seu trabalho lança mão de regras técnicas - que Ihe são ensinadas pelas escolas de Direito - que dão um cunho eminentemente tecnológico à Ciência do Direito. De fato, ele, intérprete, domina técnicas aprendidas na Ciência do Direito, para, aplicando-as ao sistema jurídico todo, extrair dele o melhor resultado - técnico - possível. Submetendo o sistema à sua forma prévia de vê-lo, o intérprete elege uma série de premissas possíveis e que surgem pela melhor ou pior manipulação de sua técnica, para, depois, por força de uma decisão, escolher a que the parece mais adequada, a que lhe surge como mais eficaz (NUNES, 2015, p. 317-318).

De acordo com o autor supramencionado, quando se fala em interpretar a norma jurídica, vale a mesma afirmação de "fixação de sentido" e, além disso, deve ser adicionada ainda a chamada "fixação do alcance" da norma. Ou seja, além de fixar o sentido sobre a norma no momento de sua interpretação, deve ser ponderado e fixado também o seu alcance, pois dessa forma deixa evidente a que situações e indivíduos a norma se aplica (NUNES, 2015, p. 317).

Tal como a sociedade que, não sendo unidade substancial, contudo por ser unidade plurissubstancial, é unidade de ordem e manifesta-se por uma personalidade moral, de modo análogo à norma, não sendo embora um ser orgânico do mundo físico, mas enquanto brota da consciência axiológica da coletividade como sua expressão viva, tem existência real e operativa (COSTA, 1996, p. 99).

O Direito é fenômeno social que tão-somente pode ser compreendido com fulcro na realidade e no processo cultural e histórico. Os sistemas jurídicos trazem o conteúdo da classe dominante na sociedade, e as ideologias do Direito refletem resultados predominante historicamente.

\section{CONCLUSÃO}

A incidência da moralidade no campo do jurídico, serve como um ponto de equilíbrio, que direciona o Direito, mecanismo de ordem social para um patamar muito mais amplo que mera conjuntura de normas juridicamente válidas, vez que mesmo no plano da validez podem incorrer no fato social como ineficazes.

As forças sociais condicionam a produção legislativa, considerando que todo poder emana do povo. E essa mesma força social, condicionada por um conjunto de ideologias e produtos culturais impulsionam a aplicação das normas, já que o julgador subsume a norma ao fato social imbuído por procedimentos ideológicos, que dependendo do caso concreto, desempenha papel terminante. 
Logo, a incidência valorativa na nomogênese e subsunção norteia a criação e a aplicação do Direito de forma a expandi-lo para além da esfera meramente normativista, tornando-o produto legítimo da condição humana, carregado de valor, que lhe dá forma, na nomogênese e sentido, na subsunção.

\section{REFERÊNCIAS}

BRASIL. Constituição da República Federativa do Brasil de 1988. Brasília: DF, Senado, 1988.

CANARIS, Claus-Wilhelm. Pensamento sistemático e conceito de sistema na ciência do Direito. Trad. Menezes Cordeiro. 3. ed. Lisboa: Fundação Calouste Gulbenkian, 2002.

COSTA, Elcias Ferreira. A essência trinitária do direito. Porto Alegre: Fabris, 1996.

FERRAZ JÚNIOR, Tércio Sampaio. A função social da dogmática jurídica. São Paulo: Atlas. 2015.

KANT, Immanuel. A metafísica dos costumes. São Paulo: Edipro, 2003.

KELSEN, Hans. Teoria pura do direito. Trad. João Baptista Machado. 6. ed. São Paulo: Martins Fontes, 1995.

MARQUES NETO, Agostinho Ramalho. A ciência do Direito: conceito, objeto, método. 2. ed. Rio de Janeiro: Renovar, 2001.

NUNES, Rizzatto. Manual de filosofia do direito. 6. ed. São Paulo: Saraiva, 2015.

PAUPÉRIO, Arthur Machado. Introdução axiológica do Direito. Rio de Janeiro: Forense, 1977.

REALE, Miguel. Filosofia do Direito. 20. ed. São Paulo: Saraiva, 2002. . Lições Preliminares do Direito. 26. ed. São Paulo: Saraiva, 2002.

VASCONCELOS, Arnaldo. Direito, Humanismo e Democracia. 3. ed. São Paulo: Malheiros, 1998. Teoria Pura do Direito: repasse crítico de seus principais fundamentos. Rio de Janeiro: Forense, 2003. 